\title{
Nonseminomatous Germ Cell Testicular Tumour With Metastatic Retroperitoneal Lymphadenopathy Presenting As Severe Backache Due To Ivc Thrombosis
}

\author{
Sanjay M. Khaladkar, Rubab Kaur Sekhon, Khushboo Agrawal, Vikas LB Jadhav, and Rajesh S. \\ Kuber
}

\begin{abstract}
IVC thrombosis is often under-recognized. Malignancy can cause spontaneous IVC thrombosis due to its prothrombotic potential. Malignant tumors can compress, adhere or infiltrate the IVC wall causing endothelial damage with subsequent thrombosis. Retroperitoneal lymphadenopathy can cause compressive distortion of IVC causing venous stasis and turbulent flow. Metastatic retroperitoneal lymphadenopathy from testicular tumor is a rare cause of IVC invasion with resultant IVC thrombosis which can rarely present as backache. High index of suspicion is needed to detect primary testicular tumor in cases of IVC thrombosis, especially in young individuals.

A 26 -year old male presented with lower back ache, weight loss and fever. MRI Lumbosacral spine done outside showed a soft tissue signal intensity retroperitoneal mass in aortocaval region compressing IVC. Ultrasound (done outside) revealed mild right sided hydroureteronephrosis secondary to a lobulated heterogeneous mass in inter-aortocaval region encasing right ureter and invading IVC causing thrombosis. Contrast enhanced Computerized axial tomography of abdomen showed a heterogeneously enhancing lobulated mass with multiple internal calcifications, in inter-aortocaval region at L3-4 level invading the IVC causing IVC thrombosis. Both tumor thrombus and bland thrombus were present. The right testis showed a subtle $10 \times 10 \mathrm{~mm}$ hypodense lesion with peripheral calcification. DW-MRI showed diffusion restriction in retroperitoneal mass and the IVC tumor thrombus. Possibility of primary testicular tumor with metastatic retroperitoneal lymphadenopathy causing IVC invasion with resultant thrombosis was considered which was confirmed on histopathological examination.
\end{abstract}

Index Terms - IVC thrombosis; non-seminomatous germ cell tumor; retroperitoneal lymphadenopathy; Testicular tumour.

Published on July 14, 2020.

S. M. Khaladkar, Dr. DY Patil Medical College, Hospital and Research center, India.

(corresponding e-mail: drsanjaymkhaladkar@gmail.com)

R. K. Sekhon, Dr. DY Patil Medical College, Hospital and Research center, India.

(e-mail: sekhon.rubab ${ }^{@}$ gmail.com)

K. Agrawal, Dr. DY Patil Medical College, Hospital and Research center, India.

(e-mail: khushbooagrawal231@gmail.com)

V. LB Jadhav, Dr. DY Patil Medical College, Hospital and Research center, India.

(e-mail: drvikasjadhav@gmail.com)

R. S. Kuber, Dr. DY Patil Medical College, Hospital and Research center, India.

(e-mail: dr.rajeshkuber@gmail.com)

\section{CASE REPORT}

A 26 years old male patient presented with lower back ache, weight loss and fever. MRI Lumbosacral spine (Fig. 1) done in an outside center showed a soft tissue signal intensity retroperitoneal mass in aorto-caval region compressing IVC- likely lymph nodal mass.

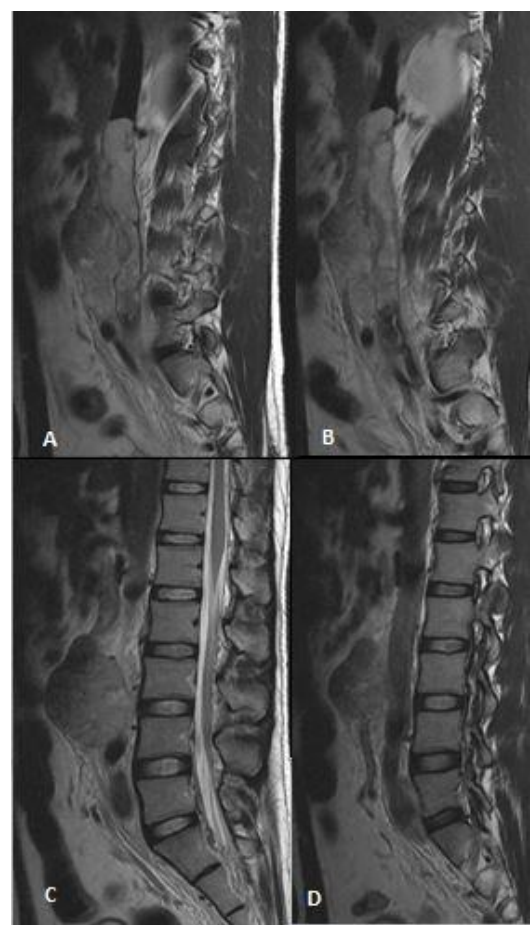

Fig. 1. MRI spine (sagittal T2WI- A-D)- showing a fairly well defined lobulated heterogeneously hyperintense soft tissue intensity mass in retroperitoneum at L3-4 level with IVC thrombosis.

Ultrasound (USG) Abdomen showed mild hydronephrosis in right kidney and mild hydroureter in upper portion. A lobulated mixed echoic mass of size $84 \times 76 \times 57 \mathrm{~mm}$ noted in retroperitoneum in inter-aortocaval region proximal to level of aortic bifurcation extending to pre-aortic and pre-caval region (Fig. 2 A-B). It showed few echoreflective foci of calcification. It appeared to be encasing/ involving adjoining right ureter causing mild hydronephrosis and proximal hydroureter. The mass was invading adjoining IVC causing IVC thrombosis. The thrombus extended proximally upto level of renal veins. Distally the thrombus extended into common iliac veins, 
right external iliac vein and right common femoral vein. USG of right testis (Fig. 2 C-D) showed a well-defined mixed echoic solid mass measuring 18 (length) x14 (anteroposterior) $\mathrm{x} 15$ (transverse) $\mathrm{mm}$ showing peripheral echoreflective calcification in its posterior portion.

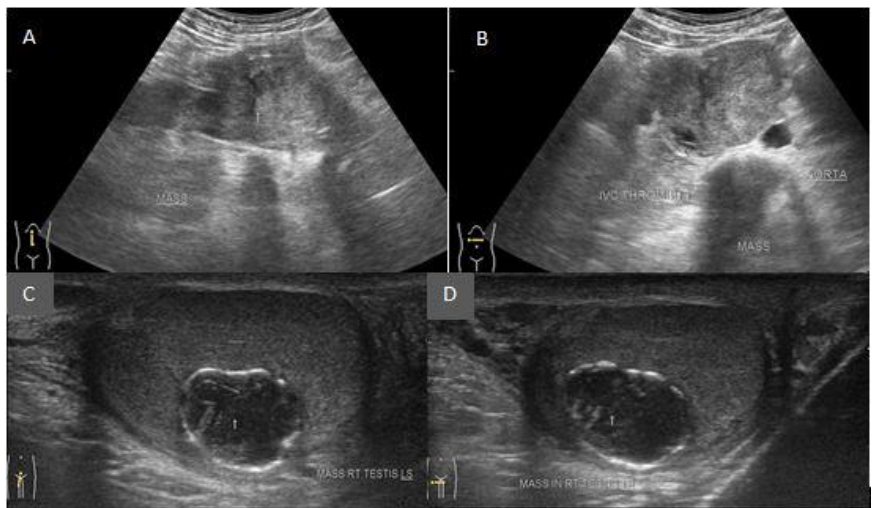

Fig. 2. Ultrasound abdomen Longitudinal (A) and transverse (B) sections showing fairly well defined solid mas of heterogeneous echotexture in retroperitoneum just proximal to level of aortic bifurcation compressing and displacing IVC towards the right, invading IVC with resultant IVC thrombosis. Ultrasound of right testis, longitudinal (C) and transverse (D) sections showing a well-defined mixed echoic, predominantly hypoechoic solid mass in right testis with peripheral echoreflective calcification.

CT Abdomen and pelvis (Figures 3-6) showed a fairly well defined lobulated soft tissue density mass measuring 77 (length) x56 (anteroposterior) x69 (transverse) $\mathrm{mm}$ in retroperitoneum in inter-aortocaval region at L3-4 level. It appeared heterogeneous in density on plain study and showed heterogeneous post contrast enhancement. Multiple small hyperdense foci suggestive of calcification were noted within the mass. The mass was extending in pre-aortic and precaval region and was causing splaying of adjoining aorta and IVC which were displaced laterally by the mass. Fat plane between the mass and right anterolateral margin of adjoining aorta was obscured. IMA was displaced towards the left by the mass with obscuration of the intervening fat planes. Fat planes between the mass and adjoining IVC was obscured with IVC invasion. Intraluminal filling defect measuring approx. 77 (length) x22(anteroposterior) $\mathrm{x} 24$ (transverse) $\mathrm{mm}$ was noted in adjoining IVC extending proximally upto opening of bilateral renal veins in IVC showing heterogeneous post contrast enhancement. This was likely to represent tumor thrombus. IVC distal to tumor thrombus showed hypodense filling defect extending into both the common iliac veins, right external iliac vein, right internal iliac vein and right common femoral vein in upper right thigh suggestive of bland thrombosis. No extension of thrombus was noted in renal veins. Rest of intrahepatic IVC, hepatic, supra-hepatic portion of IVC appeared normal. The mass was also compressing and encasing the adjoining right ureter with resultant proximal mild hydroureteronephrosis with delayed appearance of nephrogram and no excretion of contrast in PC system in delayed phase. Few subcentimeter sized enhancing lymph nodes were noted in para-aortic, paracaval, inter-aorto-caval region.
Liver and both adrenal glands appear normal. No hepatic/ adrenal metastasis was noted. A subtle well defined hypodense lesion measuring approx. 10x10 mm with peripheral calcification was noted in right testis.

Possibility of primary testicular tumor with metastatic retroperitoneal lymphadenopathy causing IVC invasion with resultant IVC thrombosis involvement of adjoining right ureter with proximal right hydroureteronephrosis was considered.

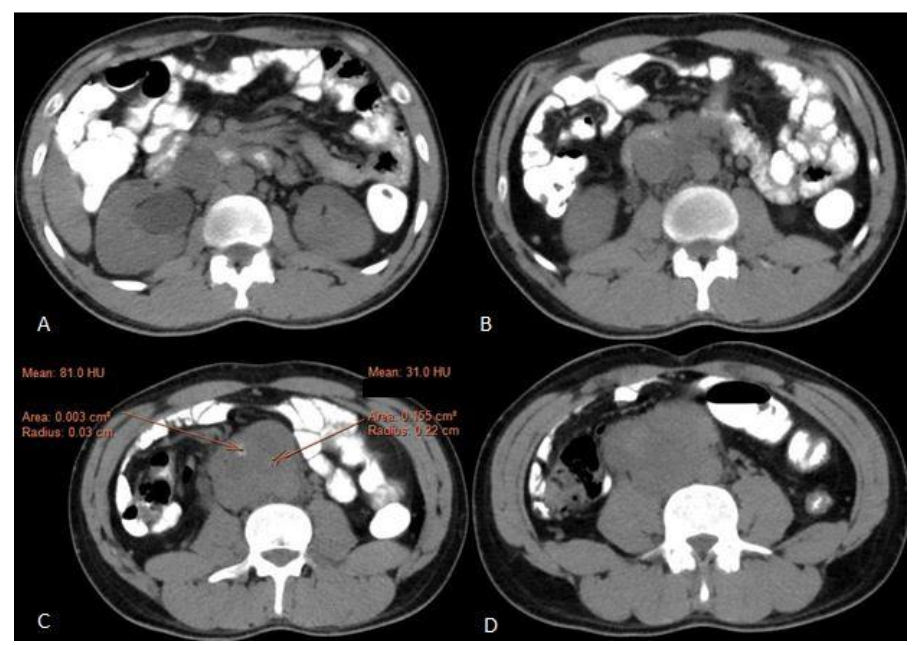

Fig. 3. Plain CT scan of abdomen (A-D)- shows a fairly well defined lobulated soft tissue density mass in retroperitoneum in inter-aortocaval region at L3-4 level. It shows multiple small hyperdense foci suggestive of calcification were noted within the mass. Right kidney shows mild hydronephrosis due to ureteric compression.

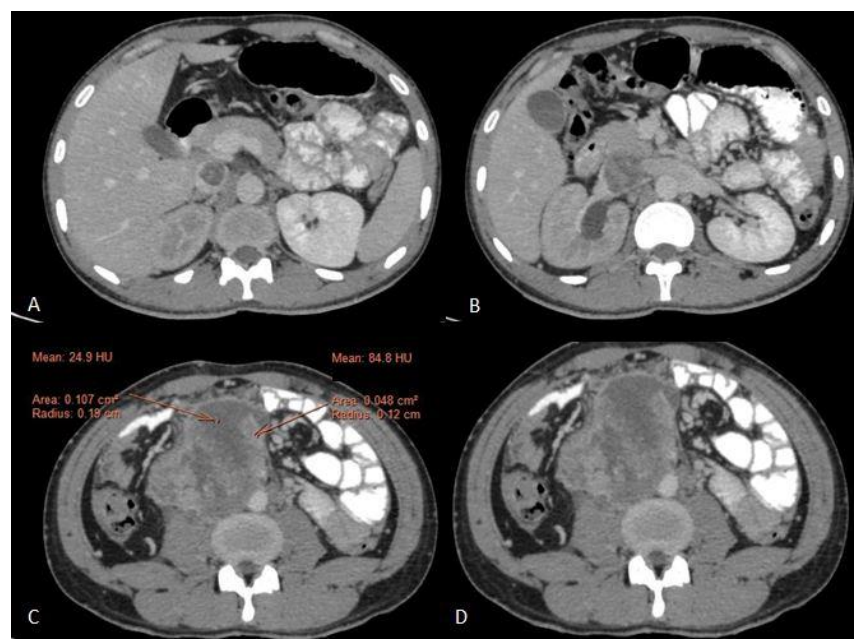

Fig. 4. Contrast enhanced axial CT scan of abdomen (A-D)- shows a fairly well defined heterogeneously enhancing lobulated soft tissue density mass in retroperitoneum in inter-aortocaval region at L3-4 level. Right kidney shows mild hydronephrosis due to ureteric compression. Filling defect noted in IVC due to thrombosis. 


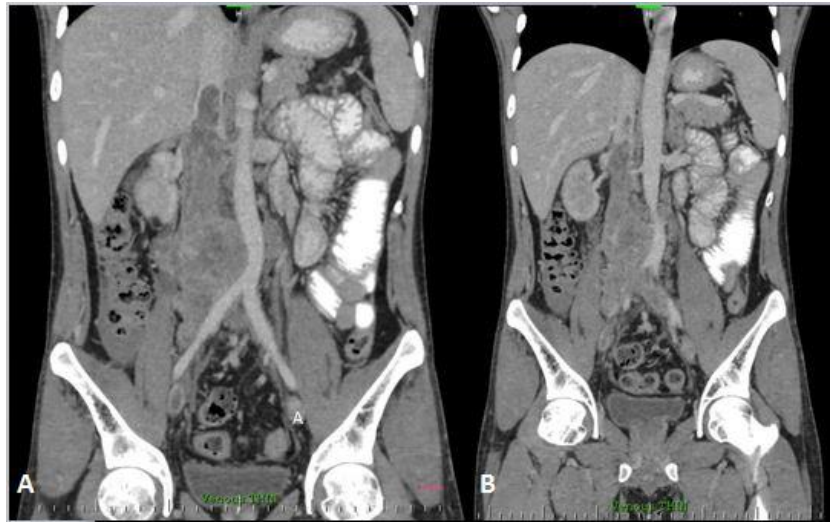

Fig. 5. Contrast enhanced CT scan of abdomen coronal images(A-B)shows a fairly well defined heterogeneously enhancing lobulated soft tissue density mass in retroperitoneum in inter-aortocaval region at L3-4 level causing mass effect on both aorta and IVC. Filling defect noted in IVC due to thrombosis extending proximally upto infrahepatic portion of IVC and inferiorly into bilateral common iliac veins.

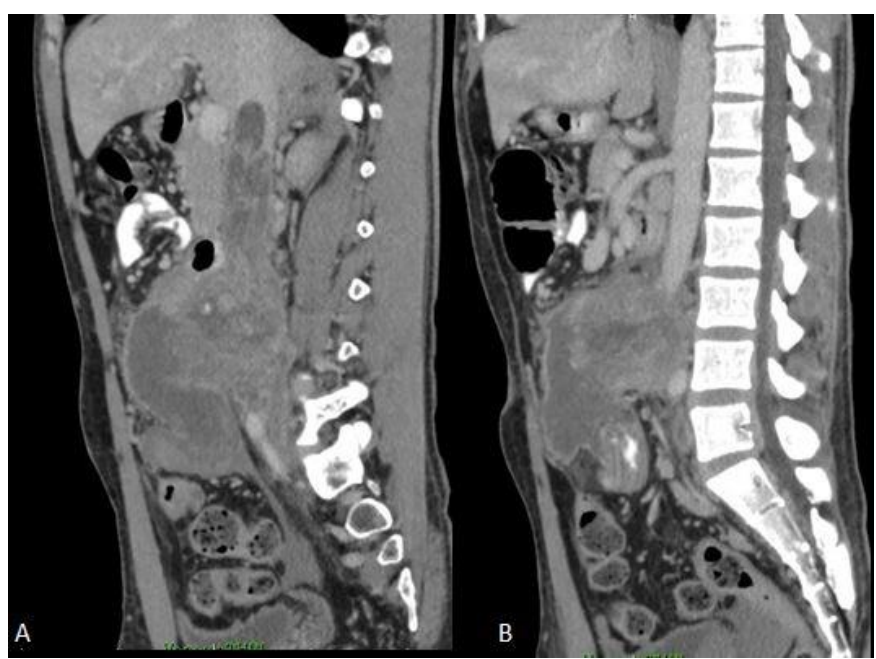

Fig. 6. Contrast enhanced CT scan of abdomen sagittal images(A-B) shows a fairly well defined heterogeneously enhancing lobulated soft tissue density mass in retroperitoneum in inter-aortocaval region at L3-4 level causing mass effect on both aorta and IVC. Filling defect noted in IVC due to thrombosis extending proximally upto infrahepatic portion of IVC and inferiorly into bilateral common iliac veins.

MRI of abdomen (Fig. 7-10) showed a fairly well defined lobulated soft tissue intensity mass in retroperitoneum in inter-aortocaval region at L3-4 level appearing isointense to muscle on T1WI and heterogeneously hyperintense on T2WI with IVC thrombosis extending proximally upto infra-hepatic portion appearing hyperintense on both $\mathrm{T} 1$ and T2WI. Right kidney shows mild hydronephrosis due to compression and encasement of adjoining right ureter .Diffusion restriction (Fig. 11) was noted in retroperitoneal mass with low ADC values suggestive of neoplastic etiology. IVC thrombus also showed restricted diffusion with low ADC value suggestive of tumor thrombus. Thrombus in distal portion of right external iliac vein and right common femoral vein did not show restricted diffusion on DWI- likely to be bland thrombus.

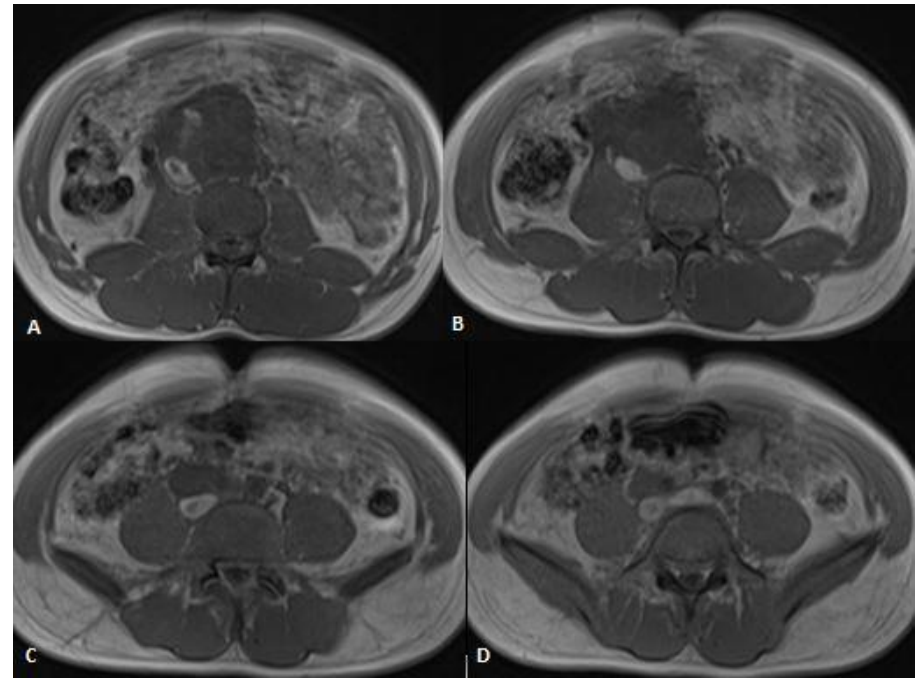

Fig. 7. MRI Abdomen Axial T1 (A-D)- shows a fairly well defined lobulated soft tissue intensity mass in retroperitoneum in inter-aortocaval region at L3-4 level appearing isointense to muscle with IVC thrombosis appearing hyperintense.
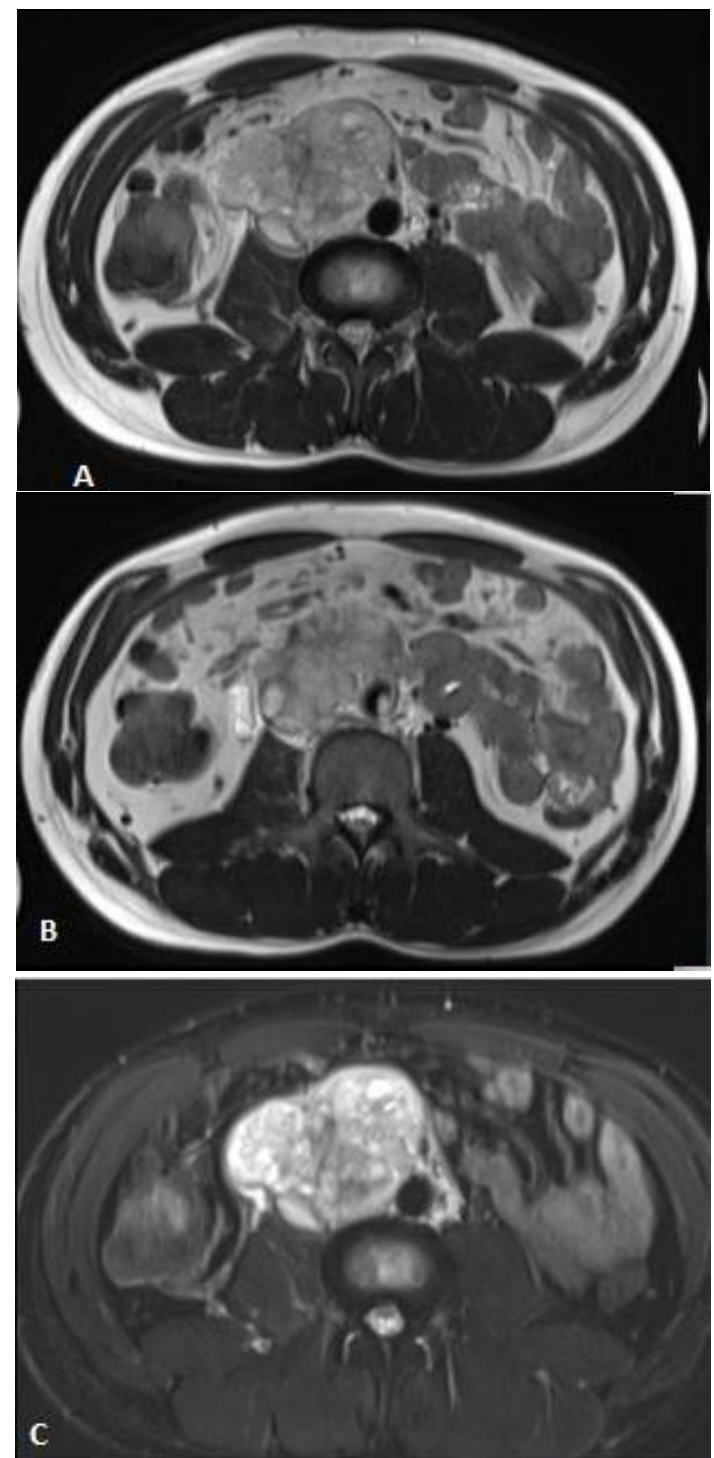

Fig. 8. MRI Abdomen Axial T2 (A-C)- shows a fairly well defined lobulated soft tissue intensity mass in retroperitoneum in inter-aortocaval region at L3-4 level appearing heterogeneously hyperintense with IVC thrombosis appearing hyperintense. 


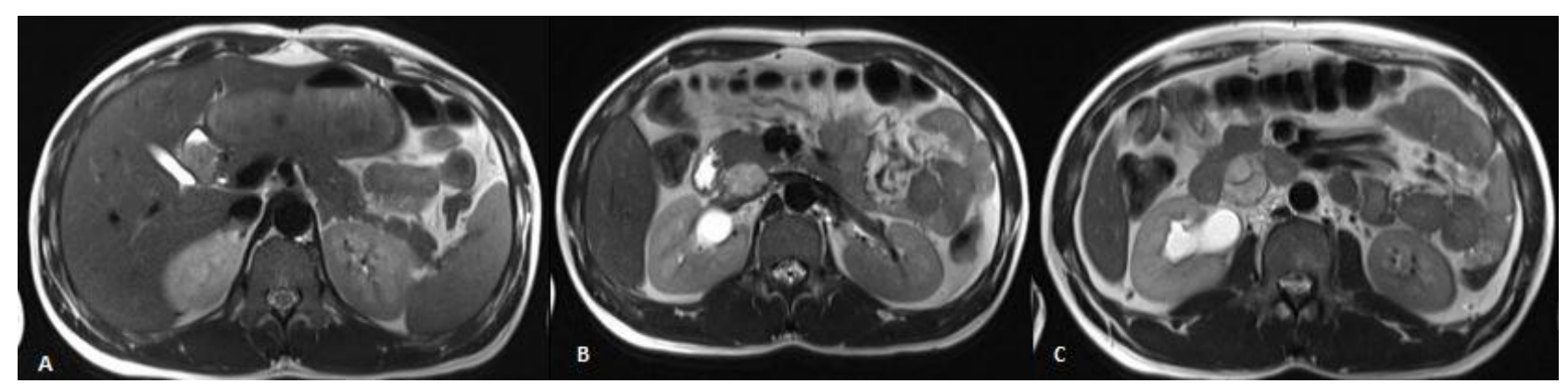

Figure 9-MRI Abdomen Axial T2 (A-C)- shows IVC thrombosis and mild hydronephrosis in right kidney due to ureteric compression.

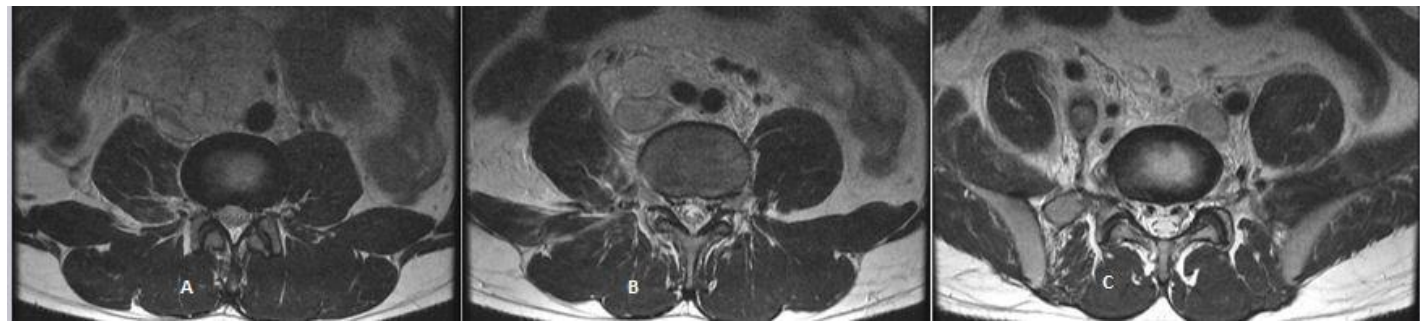

Fig. 10. MRI Abdomen Axial T2 (A-C)- shows a fairly well defined lobulated soft tissue intensity mass in retroperitoneum in inter-aortocaval region at L34 level appearing heterogeneously hyperintense with IVC thrombosis extending to bilateral common iliac veins appearing hyperintense.

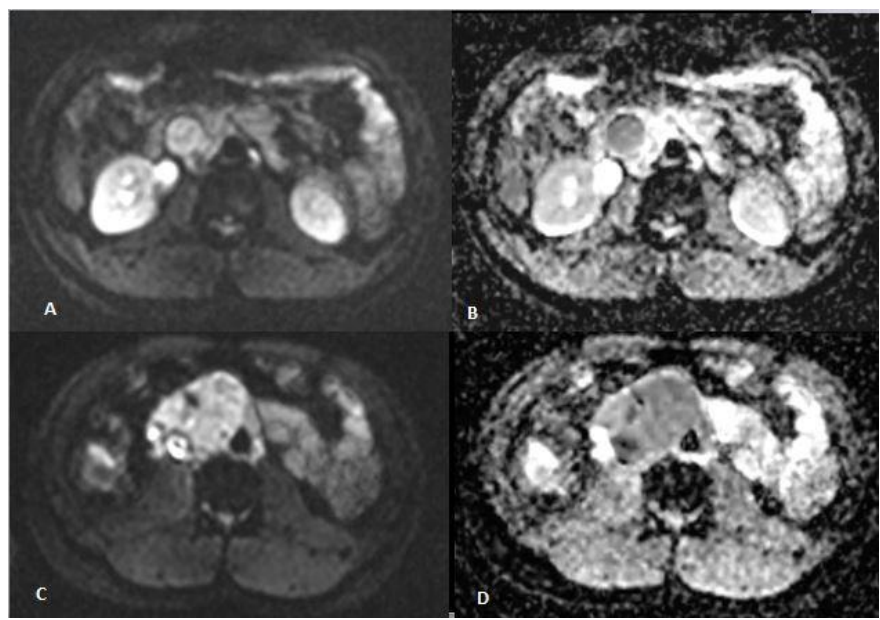

Fig. 11. MRI Abdomen Diffusion weighted imaging (A-D)- Retroperitoneal mass showing restricted diffusion on DWI (C) with low ADC value (D). IVC thrombus showing restricted diffusion on DWI (A, C) with low ADC value $(\mathrm{B}, \mathrm{D})$.

Whole body 18FDG PET-CT scan (Fig. 12) showed a well-defined heterogeneously enhancing FDG avid (SUV $\max 16.61$ ) retroperitoneal mass measuring 8.41(SI) x5.24 (AP) $x 7.39$ (TR) $\mathrm{cm}$. retroperitoneal mass encasing aorta and IVC inferior to the levels of renal veins. Tumor thrombosis of infrarenal IVC was noted. Non FDG avid thrombosis of bilateral common iliac veins, right external iliac vein, right internal iliac vein, right common femoral vein and right superficial femoral vein was also noted.

Trucut biopsy of retroperitoneal mass and IVC thrombus was done. Trucutbiopsy cores from both the sites showed metastatic deposits of non seminomatous malignant germ cell Tumor with tumor cells arranged in tubules, glands and focal retiform pattern. Cells showed large irregular vesicular nuclei and prominent pink nucleoli. Focal areas of necrosis were seen. No evidence of undifferentiated cells or heterogeneous elements seen. Findings were suggestive of metastatic deposits of non seminomatous malignant germ cell tumor (predominantly yolk sac tumor component).
AFP was $8052 \mathrm{IU} / \mathrm{mL}$ (normal range in men is $0.5-5.5$ IU/mL).S. LDH was 320 IU/L. (normal 80-230 IU/L). Beta$\mathrm{HCG}$ was $<5 \mathrm{mIU} / \mathrm{mL}$ i.e. normal.

Patient underwent right orchidectomy followed by chemotherapy.Histopathology confirmed non-seminomatous germ cell tumor.

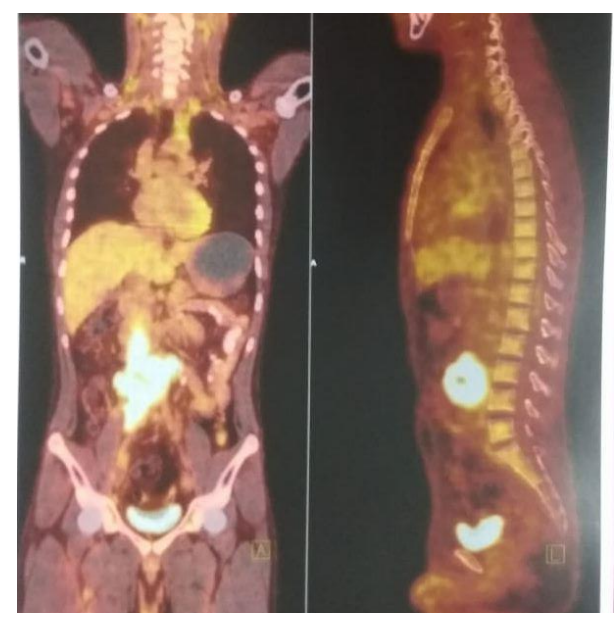

Fig. 12. PET CT showing FDG avid retroperitoneal mass in aorto-caval region and tumoral thrombus in infrarenal IVC.

\section{INTRODUCTION}

IVC thrombosis often goes undetected. Symptoms and signs are related to etiology. These range from no symptoms to cardiovascular collapse due to pulmonary embolism. Lower back pain, painful lower limb swelling, fever, dilatation of cutaneous abdominal veins and rise of inflammatory markers suggest IVC thrombosis [1].

Incidence of abdominal venous thrombosis is 1.3:1 in oncology patients undergoing cross sectional imaging. In decreasing order of frequency, IVC, renal veins and portal venous system are involved. The prevalence of thrombosis is higher in renal cell carcinoma (RCC) as compared to retroperitoneal, hepatocellular carcinoma (HCC) and metastatic liver tumors. Bland/ benign thrombosis of IVC 
occurs secondary to DVT of affected lower limbs and is often associated with risk factors like hypercoagulability, immobility and trauma [2].

Due to aggressive behavior, abdominal tumors adjacent to IVC can invade IVC. These are renal angiomyolipoma which has aggressive evolution, renal cell carcinoma, pheochromocytoma, adrenal carcinoma, hepato-cellular carcinoma, leiomyosarcoma of IVC and rarely Para neoplastic hypercoagulable state. It can occur secondary to deep vein thrombosis affecting lower limb in patients receiving long term oral contraceptives, patients with antiphospholipid syndrome, various coagulopathies and vasculitis [3].

Tumour thrombus in the IVC is a rare complication of testicular $\mathrm{Ca}$. It needs appropriate treatment with surgery and chemotherapy [4]. IVC involvement in 2 autopsy series of patients with testicular germ cell tumour was $3 \%$ and $11 \%$ of patient [5], [6]. 4 cases of IVC invasion were found in 650 patients with testicular carcinoma in whom 397 patients had retroperitoneal disease [7].

\section{DISCUSSION}

IVC thrombosis can be congenital or acquired. There is high incidence of thrombophilia in congenital IVC anomalies (like prothrombin gene mutation, protein $\mathrm{C}$ and $\mathrm{S}$ deficiency, activated protein $\mathrm{C}$ resistance, antithrombin deficiency and dysfibrinogenemia). Hence thrombophilia screening is must in patients with IVC anomalies. This occurs due to interaction between stasis and hypercoagulability [1]. Acquired IVC thrombosis occurs due to spontaneous thrombosis in normal vessel, thrombosis secondary to external vascular compression or due to pathological changes in the vessel wall [8]. Spontaneous IVC thrombosis in malignancy occurs due to prothrombotic potential of the tumor with radiotherapy and chemotherapy treatment which enhance the risk of thrombosis. Malignant tumors can compress, adhere or infiltrate the IVC wall causing endothelial damage with subsequent thrombosis. IVC thrombosis can occur secondary to abdominal trauma causing endothelial injury due to direct vessel wall injury, compression or shearing forces or intrinsic compression from adjacent hematoma. Retroperitoneal lymphadenopathy can cause compressive distortion of IVC causing venous stasis and turbulent flow [1].

IVC thrombosis in testicular tumour occurs by 2 mechanisms [4]:

A) Direct invasion of the spermatic vein and then of IVC. Hence IVC invasion is more frequent in right testicular tumour due to direct insertion of right gonadal vein into IVC.

B) Metastatic retro peritoneal lymph nodes by lymphatic spread causing Direct IVC invasion, due to development of lymphatic- venous shunting. Hence bulky metastatic retroperitoneal lymphadenopathy in testicular tumour is a major risk for IVC tumour thrombus.

IVC thrombosis can be acute or chronic. Acute IVC thrombosis can present with lower back ache and buttock pain, cauda equina symptoms and sciatica type pain. Chest pain with breathlessness can occur if there is pulmonary embolism. Patients can present with bilateral lower limb swelling with dilatation of superficial veins.

Isolated thrombosis of IVC without involvement of the iliac and femoral veins can develop collaterals along the posterior abdominal wall. If iliac or femoral veins are involved, dilated veins can appear on abdominal wall between the groin and axillae. Ascites can also develop.

Chronic IVC thrombosis occurs due to slow progressive thrombosis and can cause dull aching pain in lower limbs with symptoms of venous claudication, lower limb swelling and discomfort. These are increased by exercise and relieved by rest and elevation.

IVC thrombus can be diagnosed by ultrasound, Doppler, CT scan and MRI [9]. Duplex ultrasound is a non-invasive accurate first line investigative modality. Normally IVC shows continuous waveform with respiratory variations. These become pulsatile as IVC empties into the right atrium, with IVC thrombosis, the waveform appears monophasic. Limitations of Duplex USG are operator dependence, limitations due to overlying bowel gas and body habitus, difficulty in assessing venous compressibility. It can detect adjoining retroperitoneum, renal or adrenal mass. Dynamic CT study is non-invasive, rapid test which can detect and assess the thrombus extent along with detecting the cause of thrombosis. Both bland and tumour thrombus are seen as filling defect in IVC. Malignant thrombus shows enhancement within the filling defect and can detect contiguous adjacent mass. If adjacent tumor is not seen, then the enhancing intraluminal tumor thrombus is due to IVC leiomyosarcoma. Bland thrombus shows lack of enhancement and absence of any adjoining mass.MRI lacks radiation and is replacing $\mathrm{CT}$ as optimal non-invasive imaging tool. It can detect IVC anomalies, accurately delineate the proximal and distal extent of thrombus and its age. It can also detect morphological changes in thrombus after therapy. Availability, cost and risk of nephrogenic systemic fibrosis are the disadvantages [9].

Tumour thrombus should be differentiated from bland (benign) thrombus. Tumour thrombus will show enhancement after contrast administration like retroperitoneal mass or primary tumour. A bland thrombus will show lack of enhancement. A tumour thrombus will be FDG avid on PET CT as it is metabolically active due to trace uptake. A bland thrombus will be non-FDG avid on PET CT. On diffusion weighted MRI, the thrombus will show restricted diffusion with low ADC values [3], [18]. F FDG PET CT scan can differentiate between hyper-metabolic tumoral thrombosis and non-hyper-metabolic bland thrombosis on IVC. This helps in preventing unnecessary long-term anticoagulation treatment as tumoral thrombus does not require long term anticoagulation [10].

DW-MRI with quantification of apparent diffusion coefficients (ADC) can differentiate between malignant and bland IVC thrombosis without use of IV contrast. Malignant thrombus shows heterogenous tumor like signal on T2WI with low ADC values. Bland thrombus is iso to hypointense on T2WI and do not show restricted diffusion [2].

Ultrasound can detect size and extent of retro-peritoneal lymph nodes, their internal architecture (presence of necrosis and calcification), and presence of IVC thrombosis. Colour Doppler can be useful in differentiating between 
tumour thrombus and bland thrombus. Tumour thrombus will show vascularity while bland thrombus will show lack of vascularity.Both CT and MRI are gold standard for evaluation of retro-peritoneal disease, presence of IVC invasion and detection of IVC thrombosis with sensitivity close to $100 \%$ [11]. MRI should be obtained within 1-2 weeks in the post-operative period to rule out remaining thrombus due to aggressive nature of the tumour [12], [13].

Treatment suggested is orchidectomy and chemotherapy, retroperitoneal lymph node dissection and vascular reconstruction [14]. IVC thrombosis has a high risk of pulmonary tumoral embolism leading to death [5]. Pulmonary tumoral embolism can develop despite anticoagulation. Hence a temporary IVC filter prior to orchidectomy and chemotherapy can avoid complication of pulmonary embolism. Chances of pulmonary embolism are high when the tumour thrombus extends to right atrium ${ }^{[15]}$. In such urgent cases, thrombectomy prior to chemotherapy is needed. Initially chemotherapy followed by surgery with or without IVC filter is performed in patients with IVC thrombus without cardiac involvement. The histopathological composition of intra-luminal IVC thrombus is suggestive of type of testicular carcinoma. Best therapeutic option for such patients is aggressive surgical approach before or after chemotherapy. In majority of cases, the tumour thrombus does not regress completely after chemotherapy. Hence, surgical resection of tumour thrombus is needed.

IV. LITERATURE REVIEW

\begin{tabular}{|c|c|c|c|c|c|}
\hline Author & Year & $\begin{array}{l}\text { Age of the } \\
\text { patient }\end{array}$ & $\begin{array}{l}\text { Side and type of tumor, } \\
\text { age }\end{array}$ & Metastasis & Treatment administered \\
\hline $\begin{array}{l}\text { Geffen DB } \\
\text { et al [16] }\end{array}$ & 1992 & 34 years & $\begin{array}{l}\text { Left mixed seminoma and } \\
\text { embryonal cell testicular } \\
\text { carcinoma }\end{array}$ & $\begin{array}{l}\text { High volume retroperitoneal } \\
\text { disease, visceral metastasis, IVC } \\
\text { thrombosis extending into right } \\
\text { atrium, pulmonary embolism. }\end{array}$ & $\begin{array}{l}\text { Chemotherapy, Anticoagulants, } \\
\text { resection of residual } \\
\text { retroperitoneal mass, left radical } \\
\text { orchiectomy. }\end{array}$ \\
\hline $\begin{array}{l}\text { Fidias P et } \\
\text { al [17] }\end{array}$ & 1997 & 27 years & $\begin{array}{l}\text { Right testicular germ cell } \\
\text { tumor }\end{array}$ & $\begin{array}{lr}\text { Massive } & \text { retroperitoneal } \\
\text { lymphadenopathy, } & \text { IVC } \\
\text { thrombosis, soft tissue neck mass, } \\
\text { supraclavicular lymphadenopathy } \\
\text { with extension into mediastinum }\end{array}$ & $\begin{array}{l}\text { Anticoagulation, chemotherapy, } \\
\text { debulking and resection of } \\
\text { retroperitoneal lymph nodal } \\
\text { mass, excision of mediastinal } \\
\text { mass, right radical inguinal } \\
\text { orchiectomy. }\end{array}$ \\
\hline $\begin{array}{l}\text { Badawi JK } \\
\text { et al [18] }\end{array}$ & 2005 & 26 years & $\begin{array}{l}\text { Right testicular mixed non } \\
\text { seminomatous germ cell } \\
\text { tumor }\end{array}$ & $\begin{array}{l}\text { IVC thrombosis, retroperitoneal } \\
\text { lymphadenopathy. }\end{array}$ & $\begin{array}{l}\text { Right inguinal orchiectomy, } \\
\text { retroperitoneal } \\
\text { lymphadenectomy, extraction of } \\
\text { the IVC thrombus by cavotomy, } \\
\text { chemotherapy. }\end{array}$ \\
\hline $\begin{array}{l}\text { Kinebuchi } \\
\text { Y et al [19] }\end{array}$ & 2007 & 33 years & $\begin{array}{lll}\text { Left testicular } & \text { non } \\
\text { seminomatous } & \text { germ } & \text { cell } \\
\text { tumor } & & \end{array}$ & $\begin{array}{l}\text { Multiple metastases in both lungs, } \\
\text { retroperitoneal lymph nodes and } \\
\text { tumor thrombus in left renal vein } \\
\text { extending to the IVC. }\end{array}$ & $\begin{array}{l}\text { Left high inguinal orchiectomy, } \\
\text { chemotherapy, Retroperitoneal } \\
\text { lymph node dissection, vena } \\
\text { cavalthrombectomy. }\end{array}$ \\
\hline $\begin{array}{l}\text { Dusaud M } \\
\text { et al }[4]\end{array}$ & 2015 & 45 years & $\begin{array}{lll}\text { Left testicular } & \text { non } \\
\text { seminomatous } & \text { germ } & \text { cell } \\
\text { tumor } & & \end{array}$ & $\begin{array}{l}\text { IVC thrombosis with bilateral } \\
\text { pulmonary } \\
\text { retroperitoneal lymph } \\
\text { multiple lung metastases }\end{array}$ & $\begin{array}{l}\text { Radical orchiectomy, } \\
\text { chemotherapy, Retroperitoneal } \\
\text { lymph node dissection. }\end{array}$ \\
\hline $\begin{array}{l}\text { Raup VT et } \\
\text { al [14] }\end{array}$ & 2015 & 34 years & $\begin{array}{l}\text { Left regressed testicular } \\
\text { seminoma }\end{array}$ & $\begin{array}{l}\text { Metastasis in right kidney, Right } \\
\text { renal vein and IVC thrombosis, } \\
\text { retroperitoneal lymphadenopathy, } \\
\text { left supraclavicular } \\
\text { lymphadenopathy. }\end{array}$ & $\begin{array}{l}\text { Left inguinal orchiectomy, } \\
\text { chemotherapy, IVC filter } \\
\text { cephalad to thrombus. }\end{array}$ \\
\hline $\begin{array}{l}\text { Ucer O et al } \\
\quad[20]\end{array}$ & 2016 & 35 years & $\begin{array}{l}\text { Left testicular pure yolk } \\
\text { sac carcinoma }\end{array}$ & $\begin{array}{l}\text { Thrombus in left spermatic vein, } \\
\text { bilateral external iliac veins and } \\
\text { IVC; multiple retroperitoneal } \\
\text { lymph nodes, lung metastasis. }\end{array}$ & $\begin{array}{l}\text { Left high inguinal orchiectomy, } \\
\text { chemotherapy, anticoagulants, } \\
\text { IVC filter. }\end{array}$ \\
\hline $\begin{array}{l}\text { Sun } C \text { et al } \\
{[21]}\end{array}$ & 2017 & 32 years & $\begin{array}{l}\text { Left mixed germ cell } \\
\text { testicular tumor }\end{array}$ & $\begin{array}{l}\text { IVC thrombosis, retroperitoneal } \\
\text { lymph nodes, metastatic mass at } \\
\text { the left renal hilum }\end{array}$ & $\begin{array}{l}\text { Left inguinal orchiectomy, } \\
\text { Retroperitoneal lymph node } \\
\text { dissection, left nephrectomy, } \\
\text { IVC thrombectomy. }\end{array}$ \\
\hline $\begin{array}{c}\text { Shukla A } \\
{[22]}\end{array}$ & 2019 & 28 years & $\begin{array}{l}\text { Right testicular pure } \\
\text { embryonal carcinoma }\end{array}$ & $\begin{array}{l}\text { Metastasis to duodenum (D2/3) } \\
\text { and liver; large retroperitoneal } \\
\text { lymph nodes and thrombosis } \\
\text { involving right external iliac, right } \\
\text { internal iliac, right common iliac } \\
\text { veins extending to IVC. }\end{array}$ & $\begin{array}{l}\text { Right orchiectomy, } \\
\text { chemotherapy, anticoagulation, } \\
\text { thrombectomy. }\end{array}$ \\
\hline Our case & 2020 & 26 years & $\begin{array}{l}\text { Right testicular } \\
\text { seminomatous germ } \\
\text { tumor }\end{array}$ & \begin{tabular}{lrr} 
Metastatic & \multicolumn{2}{c}{ retroperitoneal } \\
lymphadenopathy & with & IVC \\
thrombosis. & &
\end{tabular} & $\begin{array}{l}\text { Right orchiectomy, } \\
\text { chemotherapy, anticoagulation. }\end{array}$ \\
\hline
\end{tabular}




\section{CONCLUSION}

Metastatic retroperitoneal lymphadenopathy from testicular tumor can rarely invade IVC and cause IVC thrombosis which can rarely present as backache. High index of suspicion is needed to detect primary testicular tumor in cases of IVC thrombosis, especially in young individuals Comprehensive treatment that is combination of orchiectomy, chemotherapy and anticoagulant therapy is usually considered in most of the cases.

\section{ACKNOWLEDGEMENT}

We thank Dr. Sujit Joshi (Consultant Oncopathologist) and Dr. AniruddhaKetkar (Consultant Histopathologist) of Excel Diagnostics Speciality Histopathology Centre, Erandwane, Pune for their extremely valuable contribution in the histopathological examination and diagnosis of the case.

\section{REFERENCES:}

[1] McAree BJ, O'donnell ME, Fitzmaurice GJ, Reid JA, Spence RA, Lee B. Inferior vena cava thrombosis: a review of current practice. Vascular Medicine. $2013 \mathrm{Feb}$;18(1):32-43.

[2] Osman NM, Samy LA. Benign and malignant portal venous thrombosis: Multi-modality imaging evaluation. The Egyptian Journal of Radiology and Nuclear Medicine. 2016 Jun 1;47(2):387-97.

[3] Molina M, Schiappacasse G, Labra A. Tumors that invade the inferior vena cava: an illustrative review of the main imaging features on computed tomography and magnetic resonance. Rev ChilRadiol. 2016;22:39-46

[4] Dusaud M, Bayoud Y, Desfemmes FR, Molimard B, Durand X. Unusual presentation of testicular cancer with tumor thrombus extending to the inferior vena cava. Case reports in urology. 2015;2015

[5] Bredael JJ, Vugrin D, Whitmore Jr WF. Autopsy findings in 154 patients with germ cell tumors of the testis.Cancer. 1982 Aug 1;50(3):548-51.

[6] Johnson DE, Appelt G, Samuels ML, Luna M. Metastases from testicular carcinoma study of 78 autopsied cases. Urology. 1976 Sep $1 ; 8(3): 234-9$

[7] Husband JE, Bellamy EA. Unusual thoracoabdominal sites of metastases in testicular tumors. American Journal of Roentgenology. 1985 Dec 1;145(6):1165-71.

[8] Burnand KG, Irvine AT, Wilson NM. Deep vein thrombosis: pathology. InDisease of the veins 1999 (pp. 249-289). Arnold London.

[9] Ng CS, Husband JE, Padhani AR, Long MA, Horwich A, Hendry WF, Dearnaley DP. Evaluation by magnetic resonance imaging of the inferior vena cava in patients with non-seminomatous germ cell tumours of the testis metastatic to the retroperitoneum.British journal of urology. 1997 Jun;79(6):942-51.

[10] Lai P, Bomanji JB, Mahmood S, Nagabhushan N, Syed R, Gacinovic S, Lee SM, Ell PJ. Detection of tumour thrombus by 18F-FDGPET/CT imaging.European journal of cancer prevention. $2007 \mathrm{Feb}$ 1;16(1):90-4.

[11] Agarwal S, Yadav RN, Garg G, Kumar M. Renal cell carcinoma with level 2 IVC thrombus. BMJ case reports. 2018 Jul 5;2018:bcr-2018.

[12] Constantinides C, Recker F, Bruehlmann W, Von Schulthess G, Goebel N, Zollikofer C, Jaeger P, Hauri D. Accuracy of magnetic resonance imaging compared to computerized tomography and renal selective angiography in preoperatively staging renal cell carcinoma. Urologiainternationalis. 1991;47(4):181-5.

[13] Konety BR. Multidetector computed tomography vs magnetic resonance imaging for defining the upper limit of tumour thrombus in renal cell carcinoma: A study and review: Lawrentschuk N, Gani J, Riordan R, Esler S, Bolton DM, Surgery and Urology, University of Melbourne, Austin Hospital, Heidelberg, Victoria, Australia.
InUrologic Oncology: Seminars and Original Investigations 2006 Jan 1 (Vol. 24, No. 1, pp. 84-85). Elsevier.

[14] Raup VT, Johnson MH, Weese JR, Hagemann IS, Marshall SD, Brandes SB. Seminoma presenting as renal mass, inferior vena caval thrombus, and regressed testicular mass. Case reports in urology. 2015;2015.

[15] Savarese DM, Rohrer MJ, Pezzella AT, Davidoff A, Fraire AE, Menon M. Successful management of intracardiac extension of tumor thrombus in a patient with advanced nonseminomatous germ cell testicular cancer. Urology. 1995 Dec 1;46(6):883-7.

[16] Geffen DB, Kaneti J, Hendler N, Hertzanu Y. Testicular carcinoma with inferior vena cava thrombosis extending into the right atrium treated with chemotherapy and anticoagulation. European urology. 1992;21:82-4.

[17] Fidias P, Fan CM, McGovern FJ, Wright CD, Kaufman J, Grossbard ML. Intracaval extension of germ cell carcinoma: diagnosis via endovascular biopsy and a review of the literature. European urology. 1997;31:376-9.

[18] Badawi JK, Kittner T, Manseck A, Wirth MW. Intraluminal tumour thrombus of a mixed non-seminomatous germ cell tumour of testis within the inferior vena cava.Oncology Research and Treatment. 2005;28(2):98-100.

[19] Kinebuchi Y, Ogawa T, Kato H, Igawa Y, Nishizawa O, Miyagawa SI. Testicular cancer with tumor thrombus extending to the inferior vena cava successfully removed using veno-venous bypass: A case report. International journal of urology. 2007 May;14(5):458-60.

[20] Ucer O, Nese N, Muezzinoglu T. Pure Yolk sac presenting with inferior vena cava thrombus extending from bilateral external iliac veins to hepatic vein. International braz j urol. 2016 Dec;42(6):1244 7.

[21] Sun C, Zhou J, Zhao W. Mixed germ cell testicular tumour complicated with inferior vena cava tumour thrombus: A case report and review of the literature. Biomedical Research. 2017 Jan 15;28(1).

[22] Shukla A, Chowdhury D, Mahendru V. Embryonal carcinoma testis with extensive metastasis and IVC thrombosis.Indian J PatholMicrobiol 2019;62:350-2. 